\title{
The analysis of learning needs and level of awareness for patients who underwent thoracic surgery
}

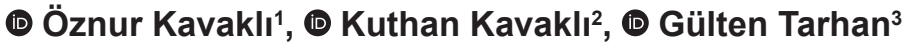 \\ 1 University Health Sciences Turkey, Gülhane Faculty of Nursing, Department of Fundamentals of Nursing, Ankara, Turkey \\ 2 University Health Sciences Turkey, Gülhane Training and Research Hospital, Clinic of Thoracic Surgery, Ankara, Turkey \\ 3Yunus Emre State Hospital, Unit of Training, Eskisehir, Turkey
}

Date submitted:

01.11.2019

Date accepted:

05.12.2019

Online publication date:

15.06.2020

\section{Corresponding Author:}

Öznur Kavaklı MD, University Health

Sciences Turkey, Gülhane Faculty of Nursing, Department of Fundamentals of Nursing, Ankara, Turkey oznur.kavakli@sbu.edu.tr

ORCID:

orcid.org/0000-0002-9670-6301

Presented in: $4^{\text {th }}$ International 23rd Congress of Balkan Military Medical Committee, 11-14 May 2018, Antalya.

Keywords: Learning needs, mindfulness, thoracic surgery

\begin{abstract}
Aims: The aim of this study is to define learning needs and level of mindfulness in patients that underwent thoracic surgery.

Methods: This cross-sectional descriptive study was conducted on 100 patients, who underwent thoracic surgery at the thoracic surgery clinic of a university hospital between December 2014 and May 2016. Data collection form consisted of three parts, namely Sociodemographic Data Form, Patient Learning Needs Scale (PLNS) and Mindful Attention Awareness Scale (MAAS).

Results: The mean age of participants was $35.74 \pm 17.87$ years and $83.8 \%$ were male. The mean score obtained from the PLNS was 200.06 \pm 37.48 . Participants obtained the highest scores from

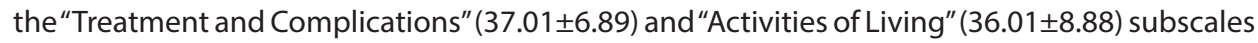
of the PLNS. The lowest score was obtained from the "Feelings related to Condition" subscale (19.01 44.75). The relationship between the socio-demographic characteristics of the patients and Patient Educational Needs Scale was not statistically significant. Besides, no statistically significant relationship was found between the scores obtained from the PLNS and MAAS.
\end{abstract}

Conclusions: Our study revealed that the majority of patients needed information on "treatment and complications". Since the levels of mindfulness of the patients may change over time, it is deemed appropriate to conduct patient education with repeated interviews.

\section{Introduction}

Recently, patients and their families want to receive high quality healthcare that is parallel to the global standards (1). They demand correct and sufficient information about health status and to actively engage in treatment process (2). Within this context, informing the patient and families about the health status of the patient is an important patient right (3). Patient education aims to correct health behaviors, helps the patients to cope with their disease and improves their skills on selfdecision-making (4). Standards for patient education have been developed and guaranteed by the JCAHO (5). Personalized and unique discharge plans have been proven to shorten hospital stay and reduce hospital readmission rates (6). Discharge education and care plans for home healthcare are highly important to prevent or reduce post-discharge complications of patients that underwent surgical operation (7). Learning needs, personal characteristics and preferences of the patients, content, place and duration of education, and available resources should be taken into consideration while determining patient education methods and techniques (8). Well-planned preoperative and postoperative pulmonary rehabilitation education programs are required to get patients that underwent thoracic surgery back to their daily lives (9). Pulmonary rehabilitation programs should be designed according to the clinical characteristics and learning 
needs of the patients (10). Patient's learning needs include the situation of disease, procedures of treatment and post-discharge homecare. Patients are mostly interested in daily activities, possible complications, drug use, access to health services, skin care, diet, exercise, wound care, and the management of pain and physical impairment. Delays in recovery, deterioration in the quality of life and increase in hospital readmission rates are observed for the patients that have not been sufficiently informed about their status by health professionals (11). Treatment and care of patients undergoing surgical operation vary depending on the type of the operation (7). In case of thoracic surgery, therapeutic compliance of patients that have received patient education are higher than those that have not. The aims of educating the patient and families include providing information about health status, increasing therapeutic compliance and enabling the patient to take the responsibility for self-care (12). Various factors, including mindful awareness, or mindfulness, influence patient education. Mindfulness, which is highly related to consciousness, is associated with maturity. "Psychological consciousness" is defined as the ability to engage in self-evaluation and perceive the relationship between emotions, ideas and behaviors in order to comprehend the reasons behind one's life and behaviors (13). Studies that evaluate the relationship between mindfulness and education show that people may not focus on the subject or remain indifferent to the education if the attractiveness of the education is not maintained. This, in turn, leads to a failure in patient education. On the other hand, attractive education programs increase mindfulness and the success rates of the program (14). Within this context, nurses should search answers the questions of "how can the patient and families be educated?" and "how do the patients learn?". They should collect information on mental competence, levels of mindfulness, and educational, sensory, psychosocial, physical and emotional development status of the patients. Identifying patients' learning needs and levels of mindfulness of the patients will contribute to positive changes in patients' attitudes and behaviors. This study aims to identify learning needs and levels of mindfulness of patients that underwent thoracic surgery.

\section{Methods}

Since this study was a non-invasive clinical research, we obtained informed consent of the participants and ethics committee approval. This study was approved by Gülhane Noninvasive Investigation Ethics Committee (8 December 2014, no: 2377).

The study was conducted on 100 patients at the thoracic surgery clinic of a university hospital. Adult patients, who were admitted to the thoracic surgery clinic of the hospital and underwent thoracic surgery during the research period, constituted the universe of this cross-sectional descriptive study. Patients above the age of 18 years, who agreed to participate, could communicate, underwent thoracic surgery and would be discharged, constituted the sample of the study. Data were collected between January 2014 and May 2016 by using faceto-face interview method. Interviews were conducted 24 hours before patient discharge. Each interview took about 15-20 minutes on average. Data collection form consisted of three parts, namely Socio-Demographic Data Form, Patient Learning Needs Scale (PLNS) and Mindful Attention Awareness Scale (MAAS). The Socio-Demographic Data Form was prepared by the researchers by using the relevant literature. The form included questions on age, gender, education, marital status, profession, people that the participants lived with, chronic diseases, smoking habits, previous admission to hospital, duration of clinical stay, and discharge education. The PLNS was developed by Bubela et al. (15). Validity and reliability of the Turkish version of the scale was performed by Catal and Dicle (16). We obtained necessary permissions to use these scales in our study. The PLNS consisted of 50 items and seven subscales. Table 1 shows the subscales, items and the minimum and maximum scores for each subscale. Items were rated on a 5-point Likert type scale ranging from 1 (of no importance) to 5 (extremely important). Patients were asked to rate the items that defined their learning needs and priorities before discharge. The scale generated subscale scores and a total scale score that ranged between 50 and 250. Cronbach's alpha for the total scale was 0.95 and ranged from 0.69 to 0.88 for the subscales.

Table 1. Patient Leaning Needs Scale, subscales, items and min.-max. scores

\begin{tabular}{llll}
\hline Subscales & Number of items & Items & Min.-max. scores \\
\hline Medications & 8 & $3,8,16,18,37,39,44,45$ & $8-40$ \\
\hline Activities of living & 9 & $2,5,14,17,27,28,29,30,48$ & $9-45$ \\
\hline Community and follow-up & 6 & $6,9,22,31,36,41$ & $6-30$ \\
\hline Feelings related to condition & 5 & $7,24,32,35,42$ & $5-25$ \\
\hline Treatment and complications & 9 & $1,4,10,19,20,23,26,38,47$ & $9-45$ \\
\hline Enhancing quality of life & 8 & $11,13,15,21,34,40,46,50$ & $8-40$ \\
\hline Skin care & 5 & $12,25,33,43,49$ & $5-25$ \\
\hline Total & 50 & & $50-250$ \\
\hline Min.: Minimum, Max.: Maximum & & & \\
\hline
\end{tabular}


The MAAS is a 15-item scale, which was developed by Brown and Ryan (17), in order to explore the presence or absence of attention to and awareness of what is occurring at the moment. Reliability and validity of the Turkish version of the MAAS was performed by Ozyeşil et al. (14). MAAS has a single factor and generates a single total score. Items are rated on a 6-point Likert scale ranging from 1 (almost always) to 6 (almost never), where higher scores indicate higher levels of mindfulness. Cronbach's alpha internal consistence coefficient of the Turkish version of the MAAS was 0.80 and test-retest correlation coefficient was 0.86 . Turkish version of the MAAS is a proper data collection tool to determine mindfulness of people in Turkish society.

We conducted a single interview with the participants before their discharge. Interviews after the patient discharge may be conducted in future research. Besides, we did not provide patient education to increase mindful awareness.

This research mainly attempts to answer the following question: "Do the levels of mindfulness influence the learning needs of the patients that underwent thoracic surgery?"

This study also attempts to answer the following subquestion: "Do the sociodemographic characteristics influence the learning needs of patients that underwent thoracic surgery?"

Expected relationships between the independent and dependent variables of this study are the followings:

$\mathrm{HO}$ : Patients with high levels of mindfulness are not aware of their learning needs.

$\mathrm{H} 1$ : Patients with high levels of mindfulness are aware of their learning needs.

Patient-centered approach has been adopted by health centers and the importance of patient engagement in healthcare has been underlined in recent years. The model, known as "Multidimensional Framework for Patient and Family Engagement in Health and Healthcare", aims to maintain active participation of the patients to clinical decisions. The model provides information about patient and family engagement at three levels, namely, direct care, organizational design and governance, and policy making. Factors related to patient, organization and the society have positive and negative effects on patient engagement. Patient education and mindfulness, which are the subjects of this research, are among the main components of active patient engagement $(18,19)$.

\section{Statistical Analysis}

SPSS 22.0 statistical software was used for data analysis. Number, percentage, mean and standard deviation were used for descriptive data. Normal distribution of continuous variables was tested with the Kolmogorov-Smirnov test. For intergroup comparison, we used the chi-square test for discrete variables and ANOVA and Student's t-test for continuous variables. Linear relationship between variables was evaluated by the Pearson correlation test. Statistical significance was set at 0.05 .

\section{Results}

The mean age of the participants was $35.74 \pm 17.87$ and $24.15 \pm 3.86$ years, respectively. The majority of the participants were male (83.8\%). More than half of the participants were single $(63.6 \%)$, and nearly half of them were graduates of secondary and high schools (47.5\%). 63.6\% were self-employed, $19.2 \%$ were civil servants and $17.2 \%$ were retired. $67.7 \%$ of the participants were admitted to the hospital for the first time. $91.9 \%$ lived with their families and $62.6 \%$ had an income that met their expenditures. $41.4 \%$ had chronic diseases, including hypertension $(n=20)$, diabetes $(n=11)$, cardiovascular diseases $(n=7)$ and chronic obstructive pulmonary disease $(n=4) .26 .3 \%$ used medications regularly. Nearly half of the participants stated that they received discharge education and one-third smoked. Descriptive characteristics of the participants are summarized in Table 2. The mean PLNS total score of the participants was $200.06 \pm 37.48$. Participants received the highest mean score

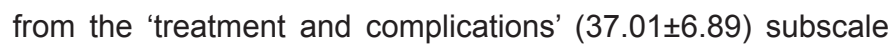
and the lowest score from the 'feelings related to condition' subscale $(19.01 \pm 4.75)$. Subscale that was scored the highest importance level was 'treatment and complications' (4.11), which was followed by 'enhancing quality of life' (4.08), and 'medications' (4.05), respectively. On the other hand, subscales that had the least mean importance levels were 'community and follow-up' (3.81) and 'feelings related to condition' (3.80), respectively. Table 3 shows the mean PLNS and MAAS scores of the patients. We did not find any statistically significant relationship between the socio-demographic characteristics of the patients and their mean PLNS scores. Besides, there was no statistically significant relationship between the mean MAAS scores and mean scores obtained from the PLNS and its subscales. Finally, we found a positive and statistically significant relationship between the total PLNS score and the scores obtained from the 'medications' $(r=0.922, p<0.001)$ and 'treatment and complications' subscales $(r=0.914, p<0.001)$.

\section{Discussion}

Patient education, which provides information to patients on their health status and treatment and recovery processes, is an important element of holistic patient care (20). It maintains active patient engagement in recovery process and helps patients to comprehend the surgical operation that they will undergo (21). Discharge education and care plans for home healthcare should be prepared to prevent or decrease complications for patients undergoing surgical operation. Discharge planning should start prior to the surgery $(7,20)$. Learning needs of the patients are knowledge and skills that are missing due to the recent developments in the lives of the patients (22). Patient education 
Table 2. Descriptive characteristics of the participants

\begin{tabular}{|c|c|c|c|}
\hline \multicolumn{4}{|c|}{ Characteristics } \\
\hline \multicolumn{2}{|c|}{ Age (Mean \pm SD) } & \multicolumn{2}{|c|}{$35.74 \pm 17.87$} \\
\hline & & $\mathbf{n}$ & $\%$ \\
\hline \multirow{2}{*}{ Gender } & Female & 16 & 16.2 \\
\hline & Male & 83 & 83.8 \\
\hline \multirow{2}{*}{$\begin{array}{l}\text { Marital } \\
\text { status }\end{array}$} & Married & 36 & 36.4 \\
\hline & Single & 63 & 63.6 \\
\hline \multirow{3}{*}{ Education } & Primary school & 26 & 26.3 \\
\hline & Secondary and high schools & 47 & 47.5 \\
\hline & University and above & 26 & 26.3 \\
\hline \multirow{3}{*}{ Profession } & Self-employed & 63 & 63.6 \\
\hline & Civil servant & 19 & 19.2 \\
\hline & Retired & 17 & 17.2 \\
\hline \multirow{2}{*}{$\begin{array}{l}\text { Admission } \\
\text { to hospital }\end{array}$} & First time & 67 & 67.7 \\
\hline & More than once & 32 & 32.3 \\
\hline \multirow{3}{*}{ Income } & Income equal to expenditure & 62 & 62.6 \\
\hline & Income less than expenditure & 26 & 26.3 \\
\hline & $\begin{array}{l}\text { Income more than } \\
\text { expenditure }\end{array}$ & 11 & 11.1 \\
\hline \multirow{2}{*}{ Living with } & Alone & 8 & 8.1 \\
\hline & Family & 91 & 91.9 \\
\hline \multirow{2}{*}{$\begin{array}{l}\text { Chronic } \\
\text { illness }\end{array}$} & Yes & 41 & 41.4 \\
\hline & No & 58 & 58.6 \\
\hline \multirow{2}{*}{$\begin{array}{l}\text { Regular } \\
\text { medication } \\
\text { use }\end{array}$} & Yes & 26 & 26.3 \\
\hline & No & 73 & 34.3 \\
\hline \multirow{2}{*}{ Smoking } & Yes & 34 & 40.4 \\
\hline & No & 65 & 65.7 \\
\hline \multirow{2}{*}{$\begin{array}{l}\text { Discharge } \\
\text { education }\end{array}$} & Received & 47 & 47.5 \\
\hline & Did not receive & 52 & 52.5 \\
\hline Total & & 99 & 100 \\
\hline
\end{tabular}

is crucial for the recovery of all patients undergoing surgical operation (12). This study identified the learning needs of the patients that underwent thoracic surgery before their discharge. We found that the participants obtained the highest scores from the treatment and complications and enhancing quality of life subscales of the PLNS. The mean total PLNS score of the participants in our study was relatively high and resembled to the findings of Catal and Dicle (16), Tan et al. (23), and Ozel (24). Studies that used PLNS for other patients in general surgery clinics also found high total PLNS scores. Similar to other studies, our study explored the need for informing the patients undergoing surgical operation and the preparation of patient education plans in line with patients' learning needs. Most of the patients in our study expressed their need to be informed about treatment and complications. Other studies, mostly on general surgery patients, had similar results. For example, the study of Tan et al. (23) on 575 general surgery patients found that the patients received the highest scores from the 'medications' and 'enhancement of quality of life' subscales of the PLNS whereas the lowest scores were received from the subscales of 'feelings related condition' and 'community and follow-up'. Similarly, the study of Ozel et al. (24) on 114 pre-discharged patients of general surgery clinic found that PLNS scores obtained from the 'medications' and 'enhancing the quality of life' were high. Deniz et al. (25) conducted a study on 57 general surgery patients and found that the most important learning needs were treatment and complications, which were parallel to our findings. Polat et al. (26) conducted a study on 1190 patients that would be discharged from a university hospital and found that 'treatment and complications' and 'skin care' were the subscales of the PLNS with the most and the least scores, respectively. Incidence of pulmonary complications after thoracic surgery, which ranges from $7 \%$ to $36 \%$, prolongs hospital stay and increases morbidity and mortality rates. Repeated patient education decreases incidences of pulmonary complications (10,27-29). Pulmonary complications are especially more important for the patients

Table 3. Average Patient Learning Needs Scale and Mindful Attention Awareness Scale scores of the participants

\begin{tabular}{llll}
\hline & $\begin{array}{l}\text { Average score } \\
\text { Mean } \pm \text { SD }\end{array}$ & Min.-max. & Importance level (mean) \\
\hline Medications & $32.42 \pm 6.48$ & $12.00-40.00$ & 4.05 \\
\hline Activities of living & $36.01 \pm 8.88$ & $14.00-91.00$ & 4.00 \\
\hline Community and follow-up & $22.91 \pm 5.18$ & $7.00-30.00$ & 3.81 \\
\hline Feelings related to condition & $19.01 \pm 4.75$ & $6.00-25.00$ & 3.80 \\
\hline Treatment and complications & $37.01 \pm 6.89$ & $14.00-45.00$ & 4.11 \\
\hline Enhancing quality of life & $32.68 \pm 6.17$ & $13.00-40.00$ & 4.08 \\
\hline Skin care & $20.00 \pm 4.01$ & $6.00-25.00$ & 4.00 \\
\hline PLNS total score & $200.06 \pm 37.48$ & $76.00-287.00$ & - \\
\hline MAAS score & $63.13 \pm 15.10$ & $36.00-144.00$ & - \\
\hline PLNS: Patient Learning Needs Scale, MAAS: Mindful Attention Awareness Scale, Min.: Minimum, Max.: Maximum, SD: Standard deviation
\end{tabular}


undergoing thoracic surgery. Discharged patients are especially nervous and demand information on how to use the ordered medications and what to do in case of complications. Patient education in thoracic surgery involves three dimensions: time required to answer the questions of the patients, information about the treatment and healthcare processes as a patient right, and content of patient education and materials. Content of patient education involves two parts: general information on thoracic surgery and information about specific surgeries, including pneumonectomy, lobectomy, wedge resection and mediastinal mass excision (20). The study of King et al. (12) on preoperative and postoperative learning needs and education given to 10 patients undergoing lung cancer surgery found that the participants found preoperative education, especially on respiratory physiotherapy, useful and expressed their learning need for postoperative pain management. On the other hand, ambulatory surgical patients have sufficient time before the operation. However, discharge education for these patients is given mostly during the postoperative period. Preoperative patient education should be simple and learning types of the patients and their satisfaction should be taken into consideration. These educations are highly important to reduce postoperative complications (28). Most of the patients that have undergone thoracic surgery have poor knowledge about modifiable life changes (30). A study on patients undergoing lung resection in the UK found that the patients identified lack of support, failure to meet patient expectations before and after surgery, underutilization of written information and their demand to face-to-face discussion with health professionals as key gaps in the experience of care (29). Our study found that the main learning needs of the participants were medications, treatment and complications and enhancing the quality of life. Patient education that deals with these subjects may contribute to patient recovery after discharge.

Discharge education that takes personal characteristics of surgical patients, including age, marital status, education, profession and prior surgical experience, into consideration are more realistic and effective to meet learning needs (31). Studies that explore sociodemographic characteristics and learning needs of the patients will have important contributions to postoperative education plans, which adapt patient demands. Our study did not find a statistically significant relationship between learning needs of the participants and their levels of mindfulness. This finding may be explained with reference to the severity of thoracic surgery, which causes anxiety and fear among the patients, irrespective of their sociodemographic characteristics. Some of the studies on sociodemographic characteristics of other surgical patients had similar findings. For example, the study of Fredericks et al. (32) that analyzed the relationship between learning needs and demographic characteristics of 38 patients, who underwent coronary artery bypass graft surgery, found no significant relationship between education levels and learning needs. However, the relationship between age, gender and cultural background of the patients and learning needs was statistically significant. Dursun and Yılmaz (33), who analyzed patients that underwent abdominal surgery found that discharge education need was higher for the graduates of high school and university. Similar to our findings, Yılmaz and Ozkan (34), and Ozkan (18) did not find a statistically significant relationship between the PLNS scores and educational levels of the patients.

Nearly $50 \%$ of the participants of our study were graduates of secondary and high schools. Our data were collected during the postoperative period. It is no accidental that participants with different educational levels shared similar ideas and feelings. In our study, participants with different sociodemographic characteristics shared similar fears and concerns before and after the thoracic surgery. Due to this reason, irrespective of their socio-demographic characteristics, all patients undergoing thoracic surgery should be provided education on subjects that will decrease their fears and concerns.

The study of Alkubati et al. (11) on patients that underwent coronary artery bypass graftsurgery found astatistically significant relationship between the learning needs and sociodemographic characteristics of the patients. Learning needs of male, younger and middle-aged, highly educated, and working patients were higher compared to female, older, uneducated and non-working patients, respectively. Another study on 1190 patients, who were planned to be discharged from different clinics, found that learning needs of the participants varied according to age, gender, profession, education, department that the patient was treated and the existence of caregiver (26). Besides, the study suggested the use of verbal questions and visual materials to explore the learning needs of the patients with lower level of education. The study of Suhonen et al. (35), which compared the information wanted and received by the patients, founded that female patients gave more importance to information and evaluation of informational areas. The study concluded that further studies to develop new methods in order to determine learning needs, evaluate the content of information and form special information packages for different patients should be conducted.

Patient learning process encompasses both preoperative and postoperative periods. During the preoperative learning period, the patient comprehends his/her role to facilitate recovery. Since thoracic surgical interventions are major interventions, patients need more information. Patient education is not completed at once; rather it is a process that covers the period from admission to hospital to the post-discharge period. Fear and concerns are widespread, especially for the patients diagnosed with tumor, since they have no knowledge about the extent or risks of planned surgery. Surgeons explain the 
risks and benefits of the surgery and the alternative treatment methods. They also answer the questions of the patients at different times. Comprehending the information provided by health professionals and processing of this information at intellectual and emotional levels takes time (20). Consequently, learning needs of the patients are influenced by their levels of perceptions (22).

This study found no statistically significant relationship between the levels of mindfulness and the learning needs of the patients. Mindfulness may be defined as "the state of being attentive to an aware of what is taking place in the present" (17). Our study conducted a single interview with the patients, who underwent thoracic surgery and would be discharged. The absence of a meaningful relation between the level of mindfulness and learning needs of the participants may be explained with reference to the absence of any intervention or education program given to the participants. In other words, mindfulness levels may change over time and the levels of mindfulness of the patients were low at the time of interviews. In order to raise their mindfulness, patient education programs on medication use and complication prevention should be conducted before hospital discharge of all patients undergoing thoracic surgery, irrespective of their sociodemographic characteristics.

\section{Conclusion}

This study did not find a statistically significant relationship between the level of mindfulness and learning needs of the participants that underwent thoracic surgery. However, the study found that most of the participants needed information on treatment and complications.

Based on the findings, we may conclude that, irrespective of their sociodemographic characteristics, level of mindfulness of patients that underwent thoracic surgery may change over time. Due to this reason, level of mindfulness at a particular time should be identified and different patient education methods should be used to increase the level of mindfulness.

\section{Ethics}

Ethics Committee Approval: The study were approved by the Gülhane Non-invasive Investigation Ethics Committee (8 December 2014, no: 2377).

Informed Consent: Consent form was filled out by all participants.

Peer-review: Externally peer-reviewed.

\section{Authorship Contributions}

Surgical and Medical Practices: K.K., Concept: Ö.K., Design: Ö.K., G.T., Data Collection or Processing: Ö.K., G.T., K.K., Analysis or Interpretation: Ö.K., K.K., Literature Search: Ö.K., G.T., Writing: Ö.K., G.T.
Conflict of Interest: No conflict of interest was declared by the authors.

Financial Disclosure: The authors declared that this study received no financial support.

\section{References}

1. Mishra PH, Gupta S. Study of patient satisfaction in a surgical unit of a tertiary care teaching hospital. J Clin Orthop Trauma. 2012;3:43-47.

2. Suhonen R, Nenonen H, Laukka A, Välimäki M. Patients' informational needs and information received do not correspond in hospital. J Clin Nurs. 2005;4:1167-1176.

3. Heneghan C. Consent to medical treatment: what should the patient be told? Br J Anaest. 1994;73:25-28.

4. Smeltzer SC, Bare B. Health Education and Promation. Brunner and Suddart's Textbook of Medical Sucigal Nursing, 10th ed. Philadelphia: Lippincott Company; 2003:40-50.

5. Root Cause Analysis in Health Care: Tools and Techniques. Accessed date: June 19, 2018. Available from: https://www. jcrinc.com/assets/1/14/EBJCIH14T.pdf

6. Shepperd S, Lannin NA, Clemson LM, Mccluskey A, Cameron ID, Barras SL. Discharge planning from hospital to home. Cochrane Database Syst Rev. 2013:CD000313.

7. Dal Ü, Bulut H, Demir SG. Problems experienced by patients after surgery at home. Med J Bakirkoy. 2012;8:3440.

8. Kelly RB, Falvo DR, Patient Education. Texbook of Family Practice, 5th ed. Philadelphia: WB Saunders Co; 1999:278290.

9. Preparation And Postoperative of Risk Reduction Strategies. www.toraks.org.tr/download.aspx?book=1818. Accessed: June 19, 2018.

10. Özalevli S. Toraks cerrahisinde postoperatif pulmoner rehabilitasyon. Thoracic Surgery Bulteni. 2015;6:16-25.

11. Alkubati SA, Al-Zaru IM, Khater W, Ammouri AA. Perceived learning needs of yemeni patients after coronary artery bypass graft surgery. J Clin Nurs. 2013;22:930-938.

12. King J, Chamberland P, Rawji A, et al. Patient educational needs of patients undergoing surgery for lung cancer. J Cancer Educ. 2014;29:802-807.

13. Sahin NH, Yeniçeri Z. Three Assessment Scales on Awareness:Psychological Mindedness, Integrative Self Knowledge and Toronto Trait Mindfulness Scales. Turkish Journal of Psychology. 2015;30:48-64.

14. Ozyesil Z, Arslan C, Kesici S, Deniz ME. Adaptation of conscious awareness scale into turkish. Education and Science. 2011;36:224-235.

15. Bubela N, Galloway S, McCay E, McKibbon A, Nagle L, Pringle D, Ross E, Shamian J. The Patient Learning Needs Scale: reliability and validity. J Adv Nurs. 1990;15:11811187. 
16. Catal E, Dicle A. Patient education requirements questionnaire validity and reliability studies in Turkey. Dokuz Eylül University School of Nursing Journal. 2008;1:19-32.

17. Brown KW, Ryan RM. The benefits of being present: mindfulness and its role in psychological well-being. J Pers Soc Psychol. 2003;84:822-848.

18. Ozkan O. Patient-focused approach to health care: patient participation. Hitit University Journal of Social Sciences Institute. 2017;10:1759-1769.

19. Carman KL, Dardess $P$, Maurer M, et al. Patient and family engagement: a framework for understanding the elements and developing interventions and policies. Health Aff (Millwood). 2013;32:223-231.

20. Bridge $\mathrm{C}$, Nelson $\mathrm{S}$. A deficit in care. the educational needs of thoracic patients. Prof Nurse. 1994;10:8-13.

21. Whyte RI, Grant PD. Preoperative patient education in thoracic surgery. Thorac Surg Clin. 2005;15:195-201.

22. Gentz CA. Perceived learning needs of the patient undergoing coronary angioplasty: an integrative reviewof the literature. Heart Lung. 2000;29:161-172.

23. Tan M, Özdelikara A, Polat H. Determination of patient learning needs. Florence Nightingale Journal of Nursing. 2013;21:1-8.

24. Ozel S. Determination of information needs of patients undergoing surgical intervention after discharge. Master Thesis, Marmara University, Istanbul, 2010.

25. Deniz S, Gezer D, Erden S, Arslan S. Assessment of learning needs in patients hospitalized in the general surgery clinic. International Journal of Caring Sciences. 2017;10:764-770.
26. Polat S, Celik S, Erkan Ha, Kasali K. Identification of learning needs of patients hospitalized at a university hospital. Pak J Med Sci. 2014;30:1253-1258.

27. Uzun O, Ucuzal M, İnan G. Post-discharge learning needs of general surgery patients. Pak J Med Sci. 2011;27:634637.

28. Liebner LT. I can't read that! Improving perioperative literacy for ambulatory surgical patients. AORN J. 2015;101:416427.

29. White J, Dixon S. Nurse led patient education programme for patients undergoing a lung resection for primary lung cancer. J Thorac Dis. 2015;7(Suppl 2):131-137.

30. Besely WNA, Mowla HAAA. Effect of standardized nursing interventions on the recovery outcomes of patients undergoing thoracic surgeries. Journal of Nursing and Health Science. 2014;3:57-69.

31. Guclu A, Kursun S. Discharge education needs of general surgery patients. Anatolian Journal of Nursing and Health Sciences. 2017;20:107-113.

32. Fredericks S, Guruge S, Sidani S, Wan T. Patient demographics and learning needs: examination of relationship. Clin Nurs Res. 2009;18:307-322.

33. Dursun HB, Yılmaz E. Learning needs of patients undergoing abdominal surgery. Celal Bayar University Institute of Health Sciences Journal. 2015;2:65-70.

34. Yılmaz E, Ozkan S. Learning needs of surgical patients. Journal of Anatolia Nursing and Health Sciences. 2015;18:107-115.

35. Suhonen R, Nenonen H, Laukka A. Välimäki M. Patients' informational needs and information received do not correspond in hospital. J Clin Nurs. 2005;14:1167-1176. 